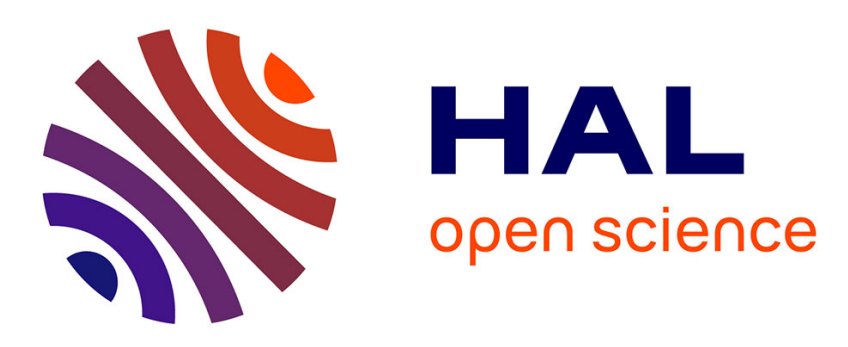

\title{
Design and evaluation of Multi-function Scanning System : a case study
}

Frédéric Vella, Damien Sauzin, Philippe Truillet, Nadine Vigouroux

\section{To cite this version:}

Frédéric Vella, Damien Sauzin, Philippe Truillet, Nadine Vigouroux. Design and evaluation of Multifunction Scanning System : a case study. 14th International Conference on Computers Helping People with Special Needs (ICCHP 2014), Jul 2014, Paris, France. pp.188-194, 10.1007/978-3-319-085999_29. hal-01178555

\section{HAL Id: hal-01178555 https://hal.science/hal-01178555}

Submitted on $20 \mathrm{Jul} 2015$

HAL is a multi-disciplinary open access archive for the deposit and dissemination of scientific research documents, whether they are published or not. The documents may come from teaching and research institutions in France or abroad, or from public or private research centers.
L'archive ouverte pluridisciplinaire HAL, est destinée au dépôt et à la diffusion de documents scientifiques de niveau recherche, publiés ou non, émanant des établissements d'enseignement et de recherche français ou étrangers, des laboratoires publics ou privés. 


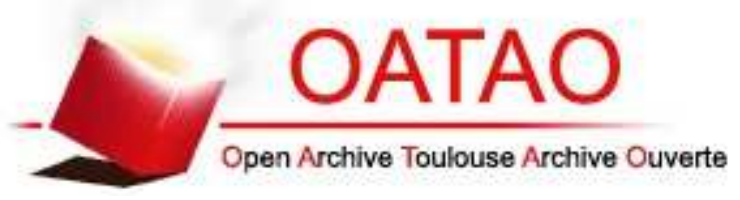

\section{Open Archive TOULOUSE Archive Ouverte (OATAO)}

OATAO is an open access repository that collects the work of Toulouse researchers and makes it freely available over the web where possible.

This is an author-deposited version published in : http://oatao.univ-toulouse.fr/ Eprints ID : 12998

URL: http://dx.doi.org/10.1007/978-3-319-08599-9_29

To cite this version : Vella, Frédéric and Sauzin, Damien and Truillet, Philippe and Vigouroux, Nadine Design and evaluation of Multi-function Scanning System : a case study. (2014) In: 14th International Conference on Computers Helping People with Special Needs (ICCHP 2014), 9 July 2014 - 11 July 2014 (Paris, France).

Any correspondance concerning this service should be sent to the repository administrator: staff-oatao@listes-diff.inp-toulouse.fr 


\title{
Design and Evaluation of Multi-function Scanning System: A Case Study
}

\author{
Frédéric Vella, Damien Sauzin, Frédéric Philippe Truillet, and Nadine Vigouroux \\ IRIT, CNRS 5505, Université Paul Sabatier, Toulouse, France \\ \{vella, sauzin, truillet, vigouroux\}@irit.fr
}

\begin{abstract}
We present in this paper an assistive technology of communication and command for quadriplegics. To carry out this assistive technology, a user centered design approach with the patient, his occupational therapists and his family was conducted. Various iterative versions of the prototype have been defined by means of the SOKEYTO platform to meet the needs and the abilities of the quadriplegic person. Options carried out and consecutive choice will be reported as well the difficulties to implement. The assistive technology was used by one quadriplegic person. A qualitative evaluation is also reported.
\end{abstract}

Keywords: Quadriplegic People, Scanning, User Centered Design, Communication, Environment Control.

\section{Introduction}

"In memory of Matthieu"

Developing scanning-based assistive systems for quadriplegic people is not a new issue. Several studies have proposed a model of man-machine interaction applied to the scanning based communication devices to adapt the scanning time based on an analysis of the data recorded in "log files" of the EDitH use [1]. Steriadis and Constantinou [8] have developed the "Autonomia" application to assist a quadriplegic person in using an ordinary personal computer. Autonomia was designed to be used through mouse and keyboard simulation through the use of specially designed "wifsids" (Widgets For Single switch Input Devices) for four frames (Cursor frame, Virtual keyboard frame, Console frame and Macros frame). Additional functionalities are also possible like dial-up connections, phones calls, etc. These solutions aim to reduce as soon as possible the expense of the cognitive load [3]. Hurst and Tobias [4] illustrates that it is possible to custom-build Assistive Technology (AT) and argues why empowering users to make their own AT can improve the adoption process. Boujrad et al. [5] have developed a participatory approach with patients and therapists to design a human computer interface for quadriplegic. Even though some work has been done, there are still needs for asking accessibility solutions for disabled people in Ambient Intelligence environments and with cheap available technologies.

Consider the case study of Matthieu. He was living in a rehabilitation center near Paris. He was a quadriplegic person without spoken communication. Matthieu had 
visual deficiency. He communicated with his family and his caregivers through his thumb movement. Matthieu only answered by two consecutive movements which mean "yes" (See Fig. 1 a). In this context, the dialog between Matthieu and his human environment -family and caregivers- was long, poor and difficult even if some facial expressions report Matthieu's intention. The learning to understand Matthieu was long time consuming.

The therapist team is heavily workloaded. In consequence Matthieu wished to be more independent and more autonomic to choose his leisure time - free to select himself the music played, the movie watched on the Web, the TV channel or the radio. He liked also to express his needs or feels as "I am cold", "I am not installed in my chair", "I want to change room", etc. to anyone.

To meet the needs of Matthieu, a user centered approach was lead including the therapist team, his father, his brother and a team specialized in the design of assistive technologies. After some observations the de-sign team has decided to design a virtual keyboard with scanning controlled by a switch connected to the input/output of a Arduino Uno box (http://www.arduino.cc).

The needs of Matthieu meet the two key issues suggested in [6] to be of primary importance, regarding the efficiency of the scan: (a) locating the target item; and (b) getting to the target item and selecting it. The first issue is affected by the appearance of the scan-items (e.g. dimensions, color, boldness, transparency etc.) while the second issue deals with the method of scan and the optimal arrangement of the items. The Information Communication Technology -Internet on TV, Ambient Intelligence, etc.- raise again needs to news services. There are technologies available at low cost.

This paper will describe how the SOKEYTO platform permits to design the Matthieu's scanning system taking into account both the issues of the user centered design step and first end-user trials. Then quantitative result about utility, utility and user satisfaction will be discussed.

\section{Architecture of the Matthieu's Scanning System}

The designed assistive technology (AT) consists of Matthieu's scanning system, a switch (See Fig. 1 b) and an Arduino box (See Fig. 1 c).

The SOftware KEYboard Toolkit (SOKEYTO v2) [7] has been used to design Matthieu's scanning system. This platform enables to design virtual keyboards for communication, environment control command, computer application like Internet or audio message linked to a key. This platform also permits to choose the type of interaction -pointing, scanning and its settings -and offer highly reconfigurable options to adapt the scanning system to the abilities of the user. All these functionalities have been used. Pictogram characteristics can be edited: color, pictogram representation, form, text and/or audio description and size as recommended by [6]. The Matthieu's scanning system exchanges with others Windows applications -like the SAPI5 component to control the Text-To-Speech (TTS) Synthesis- and the Arduino electronics prototyping platform through the through the Ivy middleware [9]. Ivy is languageindependent and allows to prototype rapidly and easily multimodal systems by exchanging text messages. 


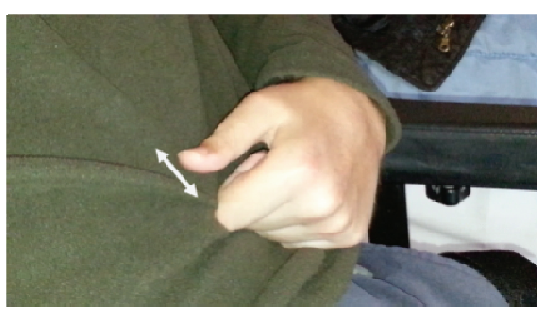

a)

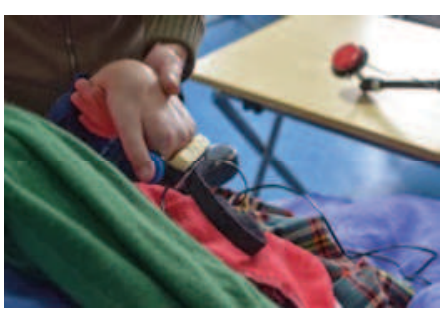

b)

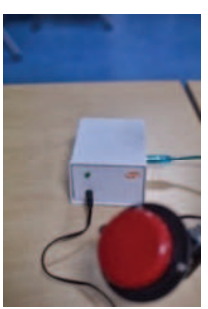

c)

Fig. 1. a) Matthieu's thumb movement, b) Matthieu's switch position, c) Switch on/off

\section{Arduino Uno Box}

The hardware part is composed of an Arduino Uno board. This board embeds a switch in order to simulate mouse clicks and two leds. The first one stands for click feedback. The second one is an InfraRed (IR) emitter to control home automation or other stuff (like control TV, radio ...). Once a double click is received from the switch, the Arduino Uno board sends data to the PC in order to control the scanning system. Finally, the board is able to receive and send IR commands from the PC (several protocols are implemented such as NEC, Sony, RC5 and raw mode). We made the choice of a low cost technology to design our scanning system. The price is around fifty Euros.

\section{$4 \quad$ User Centered Design Method}

The characteristics (pictographic representation, interaction techniques, and sound feedback) have been iteratively defined with close collaboration with the therapists and the family.

We conducted a participatory design process $[9,10]$ during six months with Matthieu. Many adaptations of the design cycle were necessary. Matthieu was personally involved to implement the "Do-It-Yourself Assistive Technology" [4]. Hence, we have proposed an approach based on high-fidelity iterative prototypes allowing both to test the design of the Matthieu's AT and to identify the interaction capabilities and needs. To maximize experience feedbacks with a minimal cost implementation, we initially used technologies "off the shelf" in particular for the hardware part. This step was very important in the definition and the criticality of the offered services.

\subsection{Pictograms}

The Matthieu's scanning system consists of 51 metaphoric pictograms. There are structured into two levels. Eight pictograms compose the first level (See Fig. 2 a) corresponding to TV channel, Internet movie, leisure and game, music, communication, phone call, and environment control. The stop pictogram interrupts the scanning. 
The other 43 pictogram corresponds to an action (for instance, selecting a pictogram to play a message). The left arrow pictogram (See Fig. $2 \mathrm{c}$ ) represents the backward to the first level of the scanning system. The current pictogram size is width $=132$ pixels and height $=132$ pixels. The visual pictogram accessibility is modifiable by adjusting the size. It is wide because the patient is visually impaired: consequently he has also difficulty focusing his eyes on the screen.

\subsection{Validation Command}

A switch is hooked on the thumb's Matthieu. Tests with a single pressure on the switch were conducted without success. In consequence, we have defined the double pressure on the switch as the validation click $(400 \mathrm{~ms})$. This double pressure is chosen to keep the current principle of communication (two movements of thumb to say "yes").

\subsection{Scanning Strategy}

The scanning is firstly performed row by row; when a row is selected, the scanning is then performed column by column. The columns are scanned only once: this option is defined to avoid cognitive overload.

The Fig. 2 a and Fig. 2 b show the visual feedback implemented. The current row scanning is identified by a red border around all pictograms (See Fig. 2 a). The current column scanning is marked by a red border around the item (See Fig. 2 b). The scanning returns in row mode if there is no selected column during a first row scanning or if a column has been selected. This setting was specific for Matthieu to minimize the number of validation in the case he does a row error. The Fig. 2 c illustrates the pictograms of the communication theme.

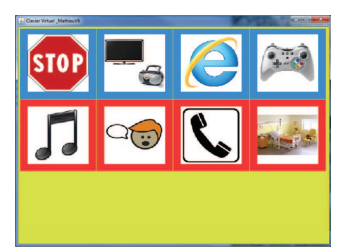

a)

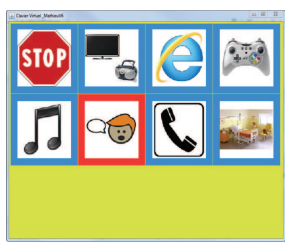

b)

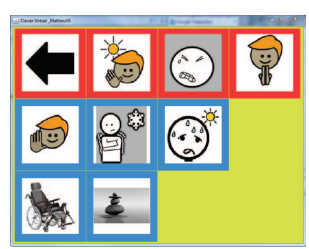

c)

Fig. 2. a) First level, row mode, b) First level, column mode, c) Second level Communication Menu

Different scanning options were available to adapt the scanning to Matthieu's abilities:

- The scanning rate;

- The automatic interruption scanning option; this option is useful when a windows application is running on the screen to avoid disturbance (from instance, sound from the scanning and sound from the movie); 
- The keyboard transparency: when this option is true, the keyboard disappears when a windows application is running; the keyboard appears again when the user clicks somewhere in the scanning system area.

\subsection{Vocal Feedback}

An oral message description is associated to each pictogram; this message could be easily modified with the SOKEYTO environment

\section{$5 \quad$ Trial Effects on the Iterative Design}

\subsection{Vocal Feedback}

Several options of pictogram reading were specially defined to address Matthieu's needs. This setting was designed to allow Matthieu to acquire the mental representation of the interactive system layout. The TTS plays all the messages of a row of pictograms. Then if a row is selected, the TTS plays pictogram per pictogram. If Matthieu selects the pictogram the TTS repeat it as a vocal validation feedback.

\subsection{Invisible Scanning System}

For instance, the validation of an Internet movie automatically generates an interruption of the scanning system. This option allows the movie in full screen and put the scanning system transparent. This option is essential to avoid disturbances between the TTS sound and the movie sound.

\section{$5.3 \quad$ Layout Keyboard}

In collaboration with the occupational therapists and the active participation of Matthieu new arrangements of the pictograms were designed. These modifications could be made in few seconds with the SoKeyTo platform. Then these layouts can be tested right now during the working sessions with the occupational therapists.

\section{Post Questionnaire about Matthieu Interactive System}

The Matthieu's system was used during two months. During these two months a lot of redesigns have made to meet the needs and the abilities of Matthieu. Three persons have answered to the questionnaire (see Table 1): Matthieu and two members of his family who taught him the use of the system. 
Table 1. Answers of post questionnaire

\begin{tabular}{|l|l|l|}
\hline \multicolumn{1}{|c|}{ Criteria } & \multicolumn{1}{|c|}{ Scale } & \multicolumn{1}{c|}{ Comments } \\
\hline Utility & Quite useful & $\begin{array}{l}\text { Scanning adjustments were needed } \\
\text { as well as the timer of the double } \\
\text { click validation }\end{array}$ \\
\hline Transparency & Quite useful & $\begin{array}{l}\text { Allows watching movies in full } \\
\text { screen and the Matthieu's interactive } \\
\text { system disappears }\end{array}$ \\
\hline Vocal restitution & Significant & $\begin{array}{l}\text { Matthieu listened more than he } \\
\text { watched the screen (partially visual- } \\
\text { ly impairment and head position) }\end{array}$ \\
\hline $\begin{array}{l}\text { Ease of memoriza- } \\
\text { tion }\end{array}$ & Neutral & $\begin{array}{l}\text { Need more time to learn the layout } \\
\text { due to visual difficulties }\end{array}$ \\
\hline Pictograms & Strongly affordance & $\begin{array}{l}\text { This feature was highly-appreciated } \\
\text { to define several semantic blocks of } \\
\text { keys. }\end{array}$ \\
\hline
\end{tabular}

Matthieu and his family have strongly appreciated the possibility of quickly adapting the interactive system. This design has demonstrated the needs to have good representation of pictograms. The vocal restitution of the pictogram made easier the training of the Matthieu interactive system.

\section{$7 \quad$ Discussion and Conclusion}

The iterative design cycle has to be adapted for our study. We had to make very many cycles between a state of the prototype and a test phase. The trials have often been partial. They often concern one dimension of the interaction: feedback, scanning, pictogram arrangement and representation, double click definition, ... because only one scanning system setting is unsuitable for the end-user. These fine settings have needed a close collaboration between the designers and the therapist team to schedule the design and test priorities. These difficulties must be considered within the deployment of a user centered method and the Do-It-Yourself Assistive Technology [4].

Our user centered approach will be deployed in order to be tested in the framework of the design of assistive technologies for Locked-In-Syndrome subjects. 


\section{References}

1. Ghedira, S., Pino, P., Bourhis, G.: Conception and experimentation of a communication device with adaptive scanning. ACM Trans. Access. Comput. 1(3), Article 14 (2009)

2. Steriadis, C.E., Constantinou, P.: Designing Human-Computer Interfaces for Quadriplegic People. ACM Transactions on Computer-Human Interaction 10(2), 87-118 (2003)

3. Niemeijer, D.: In memoriam of Bérard, C.: Striving for effort reduction through on-screen keyboard word prediction. In: Assistive Technology: from Virtuality to Reality - 8th European Conference for the Advancement of Assistive Technology in Europe (AAATE 2005), Lille, France (2005)

4. Hurst, A., Tobias, J.: Empowering Individuals with Do-It-Yourself Assistive Technology. In: ACM SIGCHI Conf. on Computers and Accessibility (ASSETS 2011), pp. 11-18. ACM, New York (2011)

5. Boujrad, A., Jouffrais, C., Truillet, P., Marque, P.: Conception d'un outil de contrôle et de communication pour personnes tétraplégiques. In: IHM 2010, Luxembourg, pp. 117-120 (2010)

6. Shein, F.: A prototype expert system for the design of a visual keyboard. In: Proceedings of the Third International Conference on Rehabilitation Engineering, Montreal, pp. 382-383 (1988)

7. Sauzin, D., Vella, F., Vigouroux, N.: SOKEYTO v2: a toolkit for designing and evaluating virtual keyboards (poster). In: European Conference for the Advancement of Assistive Technology in Europe (AAATE 2013), Vilamoura, Portugal, vol. 33, pp. 939-945. IOS Press (2013)

8. Buisson, M., Bustico, A., Chatty, S., Colon, F.-R., Jestin, Y., Maury, S., Martz, C., Truillet, P.: Ivy: Un bus logiciel au service du développement de prototypes de systèmes interactifs. In: Interaction Homme-Machine (IHM 2002), Poitiers, pp. 223-226. ACM Press (2002)

9. ISO/TR 16982:2002 Ergonomics of Human-System Interaction - Usability Methods Supporting Human-Centred Design, Switzerland (2002)

10. Mackay, W.E.: Educating Multi-Disciplinary Design Teams. In: Proc. of Tales of the Disappearing Computer, Santorini, Greece, pp. 105-118 (2003) 